\title{
THE MEASUREMENTS OF SATURATED HYDRAULIC CONDUCTIVITY OF THE FOREST FLOOR UNDER DECIDUOUS FOREST
}

\author{
Anton Zvala*, Tomáš Orfánus, Anežka Čelková
}

\begin{abstract}
The aim of the paper is to present and evaluate the measured values of saturated hydraulic conductivity of organic soil horizons under deciduous forest at the examined locality Zelezna studienka. For determination of saturated hydraulic conductivity the single ring method, the falling head method and Guelph infiltrometer were used. The organic matters of forest floor come from dead plant material at various degrees of decomposition and aggregation and significantly influence the initiation processes of infiltration and outflow. The organic soil horizons of forest floor have extremely high porosity, very low bulk density, peculiar texture and structure, are changed according to the degree of mechanical and biochemical decomposition. The average values of saturated hydraulic conductivity were measured in the range from $153.39 \mathrm{~cm} \mathrm{~h}^{-1}$ for the falling head method up to $392.1 \mathrm{~cm} \mathrm{~h}^{-1}$ for the single ring method.
\end{abstract}

KEY WORDS: infiltration measurements, saturated hydraulic conductivity, forest floor, organic soil horizons

\section{Introduction}

The saturated hydraulic conductivity $\left(K_{s}\right)$ is a quantitative characteristic of the ability to transfer water in a water saturated soil or other porous medium. It is a constant for a certain soil, but its value is different for different soils. This value depends mainly on the structure and texture of the soil. Hydraulic conductivity measurements are significantly influenced by the heterogeneity of the soil composition. The rate of water flow through the soil is strongly influenced by the presence of preferred soil paths through which the water flows faster as through the soil matrix. The value of saturated hydraulic conductivity is most influenced by the presence of preferred soil paths. The $K_{s}$ value measured in soil that does not contain preferred soil paths directly characterizes the hydraulic conductivity of the matrix. Under natural conditions, the occurrence of preferred soil paths is frequent and natural, and therefore in many cases the measured $\mathrm{K}_{\mathrm{s}}$ value characterizes the conductivity of the preferred soil paths rather than the conductivity of the matrix (Stekauerova et al., 2010). Most natural soils are neither homogeneous nor isotropic nor equally conductive in all directions. The soils are spatially variable natural units, which is caused by their genesis. Each soil type is characterized by a characteristic soil profile, thickness and development of its individual horizons. Among the other factors influencing the values of hydraulic conductivity in the forest floor are two very important characteristics: the vegetation cover and the pedogenic substrates resp. the maternal rocks from which the soil cover was evolved (Orfanus et al., 2018). Significantly, saturated hydraulic conductivity is higher in the organic horizon of forest floor, indicating that soil water fluxes are enhanced by natural vegetation cover (Pavao et al., 2019; Feng et al., 2019; Gonzales-Sosa et al., 2010).

The differences in the mother substrate, but also in vegetation on the surface of the soil, influence the existence of spatial variability of the soil, even at habitats relatively remote from each other. For this reason, the hydrophysical characteristics are also variable from one sampling point to another one (Hendrayanto et al., 2000). The spatial variability of hydraulic conductivity is manifested in both horizontal and vertical directions. The higher values of hydraulic conductivity in the vertical direction than in the horizontal direction is reflected in the structural soils, horizontal conductivity is observed in layers and oppressed soils (e.g. forest roads) (Surda et al., 2013). In addition to the mentioned spatial and temporal variability, in the case of hydraulic conductivity, there is a very high variability of values due to the methods used for its measurement and calculation, as stated Fodor et al., 2011, who found out on the scale of research areas $\left(10 \mathrm{~m}^{2}\right)$ methodological variability of hydraulic conductivity which was equals or exceeds spatial variability. This implies a difficult interpretability and comparability of the determined hydraulic conductivities between different studies as well as in relation to the ongoing process of infiltration and redistribution of 
rainwater in the soil profile.

Forest soil is a complex dynamic natural formation, constantly evolving and changing. Developed and thus optimally structured forest soils have a high organic content and a developed network of soil macropores as a result of decomposition of dead plant and animal residues and activity of soil fauna. The presence of forest litter can alter the quantities of water available for soil infiltration and runoff (Guevara-Escobar et al., 2007). Undisturbed forest soils have high infiltration capacity, reduce surface runoff, risk of erosion and retain moisture needed for vegetation (Alaoui et al., 2011).

The aim of the paper is to present the results of measurements of saturated hydraulic conductivity by various field methods in the forest floor of deciduous forest. Interpretation of these results should contribute to the explanation of the impact of organic horizon of forest floor on partial hydrological processes in forested river basins. As despite their frequent occurrence there are very few hydrological studies considering hydrophysical properties of forest floor predominantly created by plant litter, naturally stratified by varying degrees of mechanical and biochemical degradation.

\section{Material and methods}

The research site of the forest floor was Zelezna studienka in Bratislava with a species-mixed deciduous forest. The research locality is part of the Bratislava Forest Park at the end of Mlynska dolina in the Male Karpaty Mountains. The coordinates of the research site are $48^{\circ} 11^{\prime} 21^{\prime \prime}$ northern latitude and $17^{\circ} 04^{\prime} 55^{\prime \prime}$ eastern longitude. The altitude is $228 \mathrm{~m}$ above sea level. The average annual temperature of the area is $8-9^{\circ} \mathrm{C}$ and the average rainfall is in the range of $600-700 \mathrm{~mm}$ (Lapin et al., 2002). The measurements of saturated hydraulic conductivity were carried out in the year 2017.

On this research site, we found places on a slope with a sufficiently deep forest floor below the broadleaf (beech, maple, hazel). The measuring research points were placed along the way, from the recreational area to the rising spring Zelezna studienka, near to pond II. The soil cover of the immediate surroundings of these sites is made up of Dystric Cambisols, Cambi-Dystric Leptosols and Fluvisols near the Vydrica Stream (WRB, 2014). The Loess clays and sand walls occur locally as part of the slope system. The measurement sites were chosen to capture the variability of the organic horizons of forest floor in terms of their structural composition. Three measuring points (1, 2 and 3) were located near the rising spring and pond II. (a system of artificial ponds on the Vydrica Stream). This place is covered with deciduous forest dominated by beech, maple and hazel. The soil at these sites is Dystric Cambisols, acidic, loamy sand to sandy. Other measuring points (4, 5 and 6) were near the recreational facility Zelezna studienka (Fig. 1). These measuring points are characterized by a very deep forest floor with a very mixed in terms of species of plant litter. Due to gravity, the plant litter accumulates here faster than decomposition. Below this forest floor there is a thick layer organomineral $\mathrm{A}$ horizon of an acidic to very acidic soil reaction $\left(\mathrm{pH}=5.07\right.$, determined in $\left.\mathrm{H}_{2} \mathrm{O}\right)$ reaching up to a depth of $100 \mathrm{~cm}$ or more below which is the weathered parent rock (granite, pegmatite). This soil we classified as Dystric Cambisols.

The saturated hydraulic conductivity of forest floor at the points described above was determined by three methods: by a single ring infiltration method, a falling head method and a Guelph infiltrometer.

At a single ring infiltration method the metal ring of the $30 \mathrm{~cm}$ diameter and $25 \mathrm{~cm}$ height was inserted into the soil down to the required depth (to the boundary between the forest floor and the A-horizon but not less than $7 \mathrm{~cm}$ ). Perforated circular plate was inserted inside the ring, which prevented the forest floor material to be washed out during the water application onto the forest floor surface (Batkova et al., 2013). The water table (ponding) was set to $5 \mathrm{~cm}$. The time intervals, at which the water level decreased by $2 \mathrm{~cm}$ (from water level of 5 to $3 \mathrm{~cm}$ ), were recorded repeatedly until a steady flow

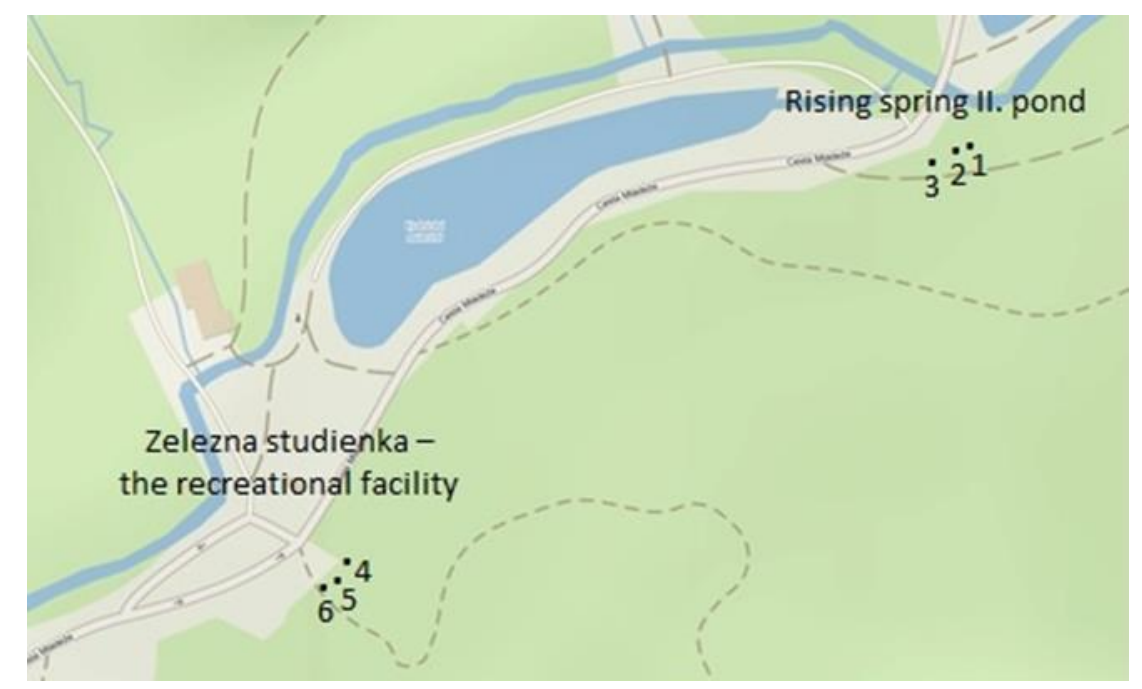

Fig. 1. Map of research site Zelezna studienka in Bratislava, Slovakia with marked measurement points. 
was achieved. From the measured values of infiltrated water volume $\mathrm{V}$ and cumulative time $\mathrm{t}$, the flow of water into the soil was calculated under conditions of steady state flow $Q$, which occurs after a longer period of infiltration. After insertion the value of depth of the ring in the soil $d(\mathrm{~L})$ and the radius of ring as to the following equation (1), the shape factor $G$ was calculated:

$G=0.316 \frac{d}{a}+0.184$

where

$G$ - the shape factor $\left[\mathrm{L}^{3} \mathrm{~T}^{-1}\right]$

$d$ - the depth of the ring in the soil [L],

$a$ - the radius of ring [L].

The saturated hydraulic conductivity $K_{s}$ (Elrick and Reynolds, 1989), was calculated by insertion of $Q, G$, the height of water level in the ring $H$ and $\alpha$ - the texture and structure dependent parameter, $\alpha=0.36$ (the coarse and gravely sands; it may also include some highly structured soils with large and/or numerous cracks, macropores, etc.) into the equation:

$$
K_{s}=\frac{Q G}{a H+a^{2} G \pi+\frac{a}{\alpha}}
$$

where

$K_{s}$ - the saturated hydraulic conductivity $\left[\mathrm{L}^{3} \mathrm{~T}^{-1}\right]$,

$Q$ - the steady state flow $\left[\mathrm{L}^{3} \mathrm{~T}^{-1}\right]$,

$G$ - the shape factor $\left[\mathrm{L}^{3} \mathrm{~T}^{-1}\right]$,

$a$ - the radius of ring [L],

$H$ - the height of water level in the ring [L],

$\alpha-$ the texture and structure dependent parameter [-].

The falling head method was used to measure the saturated hydraulic conductivity $K_{s}$ in a laboratory on $100 \mathrm{~cm}^{3}$ soil samples taken in Kopecky cylinders. The different degrees of decomposed organic material litter Duff-1 and Duff-2 into the Kopecky cylinder were taken. The litter contains the proportion of unchanged, resp. a little altered dead uncrushed organic residues. Duff-1 is composed from decay organic residues of recognizable origin; the content of amorphous matter is below $50 \%$. Duff- 2 is composed from a biochemically degraded organic residues; the content of amorphous organic matter is over $50 \%$ (Saly et al., 2014). The soil samples were taken into Kopecky cylinder, whose inner side was coated with vaseline to prevent the wall effect on infiltration measurements. The saturation of all samples was performed by gradually raising of water level in the vessel. The measurement of $K_{s}$ was realized on a device consisting of a Kopecky cylinder with a sample of soil on which we tightly attached the extension tube in form of Kopecky cylinder. Kopecky cylinder was inserted in the Petri dish with water. The extension tube was filled with water and the decrease of water level in the extension tube was repeatedly measured from the water level at the beginning of the measurement $h_{2}$ to the water level at the end of the measurement $\mathrm{h}_{1}$. To calculate $K_{s}$ by applying this method the following equation was used:

$K_{s}=\frac{l}{t} \ln \frac{h_{2}}{h_{1}}$

where

$l$ - the height of the sample in the Kopecky cylinder [L],

$t$ - the time of the water level decrease from level $\mathrm{h}_{2}$ to $\mathrm{h}_{1}[\mathrm{~T}]$,

$h_{2}$ - the water level at the beginning of the measurement [L],

$h_{l}$ - the water level at the end of the measurement [L].

The saturated hydraulic conductivity of the upper soil layer, which consisted mostly of the organic horizon of forest floor and partially encroached into the organicmineral A-horizon at the selected places, was measured by a Guelph infiltrometer. This is an experimental field method applying the principle of Marriott vessel which was inserted into the borehole with adjustable level of pond (Matula et al., 1989). The measured values of $\mathrm{K}_{\mathrm{s}}$ express the integrally vertical and horizontal hydraulic conductivity of saturated soil (Stekauerová et al., 2010). The measurements were realized in $6 \mathrm{~cm}$ and $11 \mathrm{~cm}$ deep of boreholes for each of the six measurement sites at the research locality. The depth of ponding was set to 5 $\mathrm{cm}$ and $10 \mathrm{~cm}$. To calculate the steady water discharge $(Q)$ and consequently the $K_{s}$, the equations 4-10 were used (Elrick and Reynolds, 1992). The parameter $\alpha$ was determined according to soil structure and then inserted into the equations together with the values of water head height $H_{1}=5 \mathrm{~cm}$ and $H_{2}=10 \mathrm{~cm}$ and then the shape factors $C_{1}$ and $C_{2}$ were calculated as follows:

$$
\begin{aligned}
C_{1} & =\left(\frac{\frac{H_{1}}{\alpha}}{2.074+0.093\left(\frac{H_{1}}{\alpha}\right)}\right)^{0.754} \\
C_{2} & =\left(\frac{\frac{H_{2}}{\alpha}}{2.074+0.093\left(\frac{H_{2}}{\alpha}\right)}\right)^{0.754}
\end{aligned}
$$

where

$C_{1}, C_{2}-$ the shape factor $\left[\mathrm{L}^{3} \mathrm{~T}^{-1}\right]$,

$H_{1}, H_{2}$ - the water head height [L],

$\alpha \quad-$ the radius of borehole into soil [L].

After inserting $C_{1}$ and $C_{2}$ into equations (3) and (4), we calculate $G_{1}$ and $G_{2}$.

$$
G_{I}=\frac{H_{2} C_{I}}{\pi\left(2 H_{1} H_{2}\left(H_{2}-H_{l}\right)+\alpha^{2}\left(H_{1} C_{2}-H_{2} C_{l}\right)\right)}
$$




$$
G_{2}=\frac{H_{1} C_{2}}{\pi\left(2 H_{1} H_{2}\left(H_{2}-H_{1}\right)+\alpha^{2}\left(H_{1} C_{2}-H_{2} C_{1}\right)\right)}
$$

where

$G_{l}, G_{2}$ - the two head, combined reservoir,

$H_{1}, H_{2}$ - the water head height [L],

$\pi \quad$ - the constant (Ludolf' s number, 3.14),

$\alpha \quad-$ the radius of borehole into soil [L].

The measurement data of steady flow rate $R_{1}$ and $R_{2}$ obtained from the Guelph infiltrometer were inserted into equations $Q_{1}$ and $Q_{2}$ :

$Q_{1}=R_{1} 35.22$

$Q_{2}=R_{2} 35.22$

where

$Q_{1} \quad$ - the steady state infiltration flow rate $\left[\mathrm{L}^{3} \mathrm{~T}^{-1}\right]$ for setting water head height $H_{l}$,

$Q_{2} \quad$ - the steady state infiltration flow rate $\left[\mathrm{L}^{3} \mathrm{~T}^{-1}\right]$ for setting water head height $\mathrm{H}_{2}$,

$R_{1}, R_{2}$ - the steady flow rate from the Guelph infiltrometer $\left[\mathrm{L} \mathrm{T}^{-1}\right]$.

The saturated hydraulic conductivity $K_{s}$ was calculating by using $Q_{1}, Q_{2}$ and $G_{1}, G_{2}(10)$ :

$K_{s}=G_{2} Q_{2}-G_{1} Q_{l}$

where

$K_{s} \quad-$ the saturated hydraulic conductivity $\left[\mathrm{L} \mathrm{T}^{-1}\right]$.

\section{Results and discussion}

The saturated hydraulic conductivity measurements in the deciduous forest were performed at Zelezna studienka (Bratislava) in the Male Karpaty Mountain landscape. The measurements were carried out in the year 2017. The results of the measurements of $K_{s}$ values of the forest floor under the deciduous vegetation at the research sites by a single ring infiltration method, a falling head method and by a Guelph infiltrometer, are presented in Table 1.

The graphical expression of $K_{s}$ values which were found at all six measurement points by a single ring infiltration method, a falling head method and by a Guelph infiltrometer, are presented in Fig. 2.

The results of the measurements of the saturated hydraulic conductivity of the forest floor under the deciduous vegetation at the research site by various methods can be evaluated as follows:

At first glance, the forest floor in the deciduous forest differs from the coniferous forest. We can see higher variability of litter and much released structure of organic material, from which we can suppose higher number of soil macropores and preferred soil paths. The aggregation of litter is very weak. Using a single ring method, the values of saturated hydraulic conductivity from $K_{s}=53.91 \mathrm{~cm} \mathrm{~h}^{-1}$ to $1018.73 \mathrm{~cm} \mathrm{~h}^{-1}$ were observed. This indicates a higher variability of forest floor in deciduous forest. Using by this method, the average value of $K_{s}$ of $392.1 \mathrm{~cm} \mathrm{~h}^{-1}$ was detected. The results of $K_{s}$ measurements by using a single ring method for the organic horizon of the deciduous forest are given in Table 1.

The average value of $K_{s}$ which was measured by the falling head method was $K_{s}=153.39 \mathrm{~cm} \mathrm{~h}^{-1}$. As in the coniferous also in the deciduous forest, it has been confirmed that the litter had the highest hydraulic conductivity, the lower values had Duff-1 and the lowest values of $K_{s}$ we have measured for the Duf-2 (Zvala et al., 2017). For example, for the measurement point 1, the saturated hydraulic conductivity values for litter $K_{s}=227.48 \mathrm{~cm} \mathrm{~h}^{-1}$ were found, for Duff-1 $K_{s}=25.89$ $\mathrm{cm} \mathrm{h}^{-1}$, and for Duff- $2 K_{s}=6.49 \mathrm{~cm} \mathrm{~h}^{-1}$. In the research of Duff-2, we determined significantly lower values of saturated hydraulic conductivity compared to litter. During the measurement it was seen that the leaf structure of the litter can fill the inner diameter of the Kopecky cylinder and thus prevent the infiltration. We consider the falling head method the least suitable for measuring the saturated hydraulic conductivity of forest floor in deciduous forest. Significant deceleration of the infiltration of the Duff-2 layer (due to decomposed organic matter and water repellency of substances contained in the organic horizon), can cause shallow subsurface runoff that has natural character and normally does not have harmful effects. This component of the runoff causes a significant transport (wash) of the organic horizon of forest floor during heavy floods, which can be observed in the forest after extreme rainfall events In conjunction with slope failures (such as forest roads) probably also it contributes to the overall acceleration runoff process during floods.

The average value of $\mathrm{K}_{\mathrm{s}}$ observed in six measuring points by using the Guelph infiltrometer, was $K_{s}=217.8 \mathrm{~cm} \mathrm{~h}^{-1}$. The variability of the texture and structure of the forest floor environment influence the measurement results. It can be stated that, when we measured the value of $K_{s}=20.4 \mathrm{~cm} \mathrm{~h}^{-1}$, in one case of measurement by the Guelph infiltrometer, the litter created a continuous compressed layer of leaves, which inhibit water infiltration to the forest soil. This phenomenon can even cause surface runoff in nature, as reported in the paper (Capuliak et al., 2008). The thickness of the litter layer is very different and it is exposed to natural conditions of wind, rain and accumulation at various places. Large differences in the measured results of $K_{s}$ from $K_{s}=20.4$ $\mathrm{cm} \mathrm{h}^{-1}$ to $449.4 \mathrm{~cm} \mathrm{~h}^{-1}$ are due to the uneven thickness of the forest floor, the different composition and degree of decomposition of litter in deciduous forest. The organomineral A-horizon also has water repellency in seconds to tens of seconds, and the material is not quite rigid either.

The measured average values of saturated hydraulic conductivity of the organic forest floor horizon for various measurement methods are significantly higher compared to values of saturated hydraulic conductivity of mineral soils (sandy, loam, clay). For illustration, the values of saturated hydraulic conductivity for mineral soils with different textures are presented in Table 2.

The measurement of unsaturated hydraulic conductivity using the disk infiltrometer method used in the coniferous 
forest (Zvala et al., 2017) is suitable for imitating the natural weather conditions under rain, with a relatively saturated soil profile but without forming a surface deposit. However, the method is quite unsuitable for measurements in deciduous litter, since, due to the structure of the deciduous litter, it is technically impossible to ensure surface contact of the infiltration disk with this material.

Table 1. The results of measurements of saturated hydraulic conductivity Ks by various methods at six measuring points at the research site (Fig. 1)

\begin{tabular}{|c|c|c|c|c|}
\hline \multirow{3}{*}{$\begin{array}{c}\text { Measuring point } \\
1\end{array}$} & \multirow{3}{*}{$\begin{array}{c}\text { Single ring method } \\
K_{s}\left[\mathrm{~cm} \mathrm{~h}^{-1}\right] \\
53.91\end{array}$} & \multirow{2}{*}{\multicolumn{2}{|c|}{$\frac{\text { Falling head method }}{K_{s}\left[\mathrm{~cm} \mathrm{~h}^{-1}\right]}$}} & \multirow{3}{*}{$\begin{array}{c}\text { Guelph infiltrometer } \\
K_{s}\left[\mathrm{~cm} \mathrm{~h}^{-1}\right] \\
211.81\end{array}$} \\
\hline & & & & \\
\hline & & $\begin{array}{l}\mathrm{L} \\
\mathrm{D} 1 \\
\mathrm{D} 2\end{array}$ & $\begin{array}{r}227.48 \\
25.89 \\
6.49\end{array}$ & \\
\hline 2 & 1018.73 & $\begin{array}{l}\text { L } \\
\text { D1 } \\
\text { D2 }\end{array}$ & $\begin{array}{r}176.16 \\
30 \\
7.06\end{array}$ & 180.47 \\
\hline 3 & 447.19 & $\begin{array}{l}\mathrm{L} \\
\text { D1 } \\
\text { D2 }\end{array}$ & $\begin{array}{r}463.86 \\
53.22 \\
18.95\end{array}$ & 20.40 \\
\hline 4 & 348.73 & $\begin{array}{l}\text { L } \\
\text { D1 } \\
\text { D2 }\end{array}$ & $\begin{array}{l}675.66 \\
123.07 \\
104.11\end{array}$ & 267.61 \\
\hline 5 & 179.21 & $\begin{array}{l}\mathrm{L} \\
\mathrm{D} 1 \\
\mathrm{D} 2\end{array}$ & $\begin{array}{r}178.54 \\
66.52 \\
8.03\end{array}$ & 177.63 \\
\hline $6^{*}$ & 304.76 & $\mathrm{~L}$ & 60.77 & 449.45 \\
\hline $\begin{array}{l}\text { The average value } \\
\text { of } K_{s}\left[\mathrm{~cm} \mathrm{~h}^{-1}\right]\end{array}$ & 392.1 & & 9.12 & 217.91 \\
\hline
\end{tabular}

L-Litter, D1 - Duff-1, D2 - Duff-2

*The layers D1 and D2 at measurement point 6 were not developed at the organic horizon.

There was already mineral soil under the L-layer.

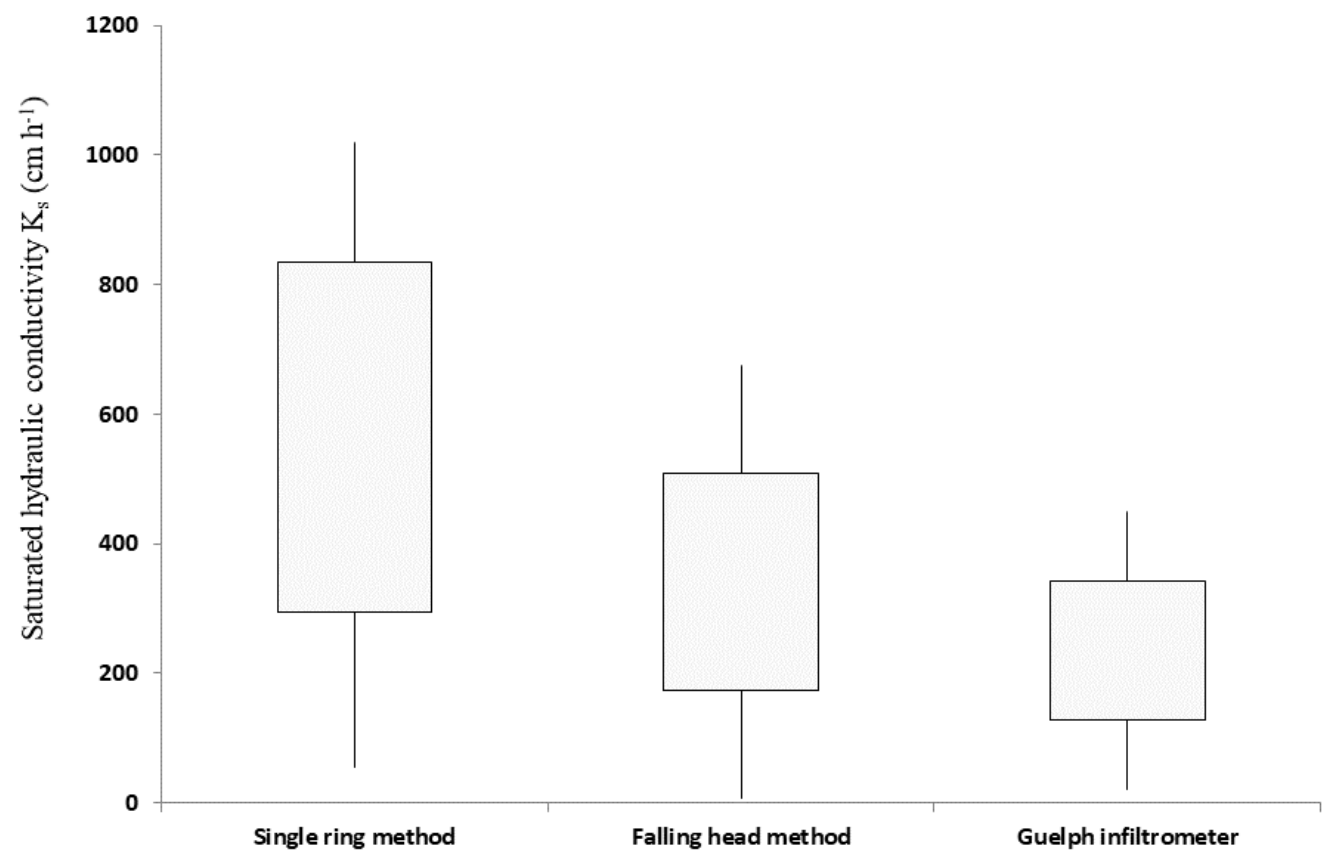

Fig. 2. Graphical display of saturated hydraulic conductivity Ks values measured by different methods (Zelezna studienka, 2017). 
Table 2. The characteristic values of saturated hydraulic conductivity $K s$ for mineral soils with different grain composition (Novák and Hlaváčiková, 2016)

\begin{tabular}{ll}
\hline Soil texture & $K_{s}\left[\mathrm{~cm} \mathrm{~h}^{-1}\right]$ \\
\hline Sandy soil & $4.16-20.83$ \\
Sandy - loam soil & $1.25-4.16$ \\
Loam soil & $0.42-2.08$ \\
Clay - loam soil & $0.21-1.25$ \\
Clay soil & $0.01-0.42$ \\
\hline
\end{tabular}

\section{Conclusion}

The observed values of saturated hydraulic conductivity of the forest floor determine important facts in terms of studying hydrological processes in forested river basins. The measuring by using the falling head method is influenced by the large area of the leaf structure, which can slow down the saturated hydraulic conductivity measured in the Kopecky cylinder. The representativeness of the saturated hydraulic conductivity value of the $100 \mathrm{~cm}^{3}$ soil sample in the Kopecky cylinder and the generalization to the entire organic horizon of forest soil is questionable. For the organic horizons we recommend to use rather a method that uses undisturbed samples of larger volume. From different measured values of hydraulic conductivity by variable hydraulic slope for different layers of organic horizon in deciduous forest, it can be stated that hydraulic conductivity is not the same throughout the organic horizon but decreases from top to bottom so how the degree of decomposition and aggregation of organic material (litter, Duff-1, Duff- 2) increases.

The measurements of $K_{s}$ using the single ring method and the Guelph infiltrometer, show the high variability of the measured values of the saturated hydraulic conductivity of the forest floor of the deciduous forest. These differences in the measured values of saturated hydraulic conductivity can be justified by the interaction of several factors with different influences in the individual measurement methods such as specific texture and structure of the organic horizon, high porosity, continuous compressed the leaf structure, different soil moisture, different hydrophobicity of organic horizon and organomineral A-horizon, different installation depths for the Guelph infiltrometer method and the single ring method.

In addition, it can be stated that in the organic horizons in the research site, a substantial part of the water flows through the macropores and the preferred paths than through the soil matrix, which theoretically can help replenish the ground water reservoirs.

Forest floor of deciduous forest is of great importance for rainwater distribution between infiltration, evaporation (including interception), water retention and runoff processes. Combination of saturated hydraulic conductivity determination by several methods enables to identify possibilities of implementation of initiation processes on the surface of forest soil during transformation of precipitation into infiltration and runoff.

\section{Acknowledgement}

This publication is the result of the project implementation ITMS 26210120009 Infrastructure completion of hydrological research stations, supported by the Research \& Development Operational Programme funded by the ERDF. Authors would like to express thanks to the Grant VEGA for the financial support from project VEGA 2/0096/19.

\section{References}

Alaoui, A., Caduff, U., Gerke, H. H., Weingartner, R. (2011): Preferential Flow Effects on Infiltration and Runoff in Grassland and Forest Soils. Vadose Zone Journal, Vol. 10, Issue 1, 367-377, DOI: 10.2136/vzj2010.0076.

Batkova, K., Matula, S., Mihalikova, M. (2013): Multimedial Study Guide of Field Hydropedological Measurements. 2nd revised edition [on-line]. English version. Czech University of Life Sciences Prague. Prague, Czech Republic. No pagination. Available at: http://hydropedologie.agrobiologie.cz. ISBN: 978-80-213-2434-3.

Capuliak, J., Homolák, M., Ascherbrenner, Š., Ahmed, Y. A. R., Královič, R. (2008): Influence of litter on initial water transport in soil under forest stand. In: Hydrology of small catchment 2008. Institute of Hydrodynamics, AVČR, 5764.

Elrick, D. E., Reynolds, W. D. (1989): Water Flux Components and their measurements. Proc. App. Soil Physics in Stress Enviroments. Jan 22-26 NARC. Islamabad, Pakistan. p. 183.

Elrick, D. E., Reynolds, W. D. (1992): Methods for analysing constant head well permeameter data. Soil Science Society of America Journal, 56, 309-312.

Feng, G., Adeli, A., Read, J., McCarty, J., Jenkins, J. (2019): Consequences of pelletized poultry litter applications on soil physical and hydraulic properties in reduced tillage, continuous cotton system. Soil\&Tillage research, Vol. 194, Article Number: 104309, 974-983 DOI: 10.1016/ j.still.2019.104309.

Fodor, N., Sándor, R., Orfánus, T., Lichner, L., Rajkai, K. (2011): Evaluation method dependency of measured saturated hydraulic conductivity. Geoderma, 2011, Vol. 165, No. 1, 60-68.

Gonzales-Sosa, E., Braud, I., Dehotin, J., Lassabatère, L., Angulo-Jaramillo, R., Lagouy, M., Branger, F., Jacqueminet, C., Kermadi, S., Michel, K. (2010): Impact of land use on the hydraulic properties of the topsoil in a small French catchment. Hydrological Processes, Vol 24, Issue 17, 2382-2399, DOI: 10.1002/hyp.7640.

Guevara-Escobar, A., Gonzalez-Sosa, E., Ramos-Salinas, M., Hernandez-Delgado, G. D. (2007): Experimental analysis of drainage and water storage of litter layers. Hydrology and earth system sciences. Vol. 11, Issue 5, 1703-1716, 
DOI: 10.5194/hess-11-1703-2007.

Hendrayanto, D., Kosugi, K., Mizuyama, T. (2000): Scaling hydraulic properties of forest soils. Hydrological Processes. Vol. 14, Issue 3, 521-538, DOI: 10.1002/ (SICI)1099-1085(20000228)14:3<521:AID-HYP952> 3.0.CO;2-C

Matula, S., Semotan, J., Vesela, J. (1989): Hydropedology practice. Czech Technical University in Prague, Faculty of Civil Engineering, ČVUT, Publishing Center, ISBN 8001-00031-1, p. 147. (In Czech)

Novák, V., Hlaváčiková, H., (2016): Soil hydrology. Institute of Hydrology SAS. VEDA, publischers Slovak Academy of Sciencies, 2016, ISBN 978-80-224-1529-3, p. 350.

Orfánus, T., Zvala, A., Nagy, V., (2018): Water infiltration into forest soil - what do the measurements signal? Current problems of the soil aeration zone under conditions of ongoing climate change. Science, Bratislava 2018, 54-79. ISBN 978-80-224-1690-0

Pavao, L. L., Sanchez, L., Pinto, O. O., Spolador, J. (2019): The influence of litter on soil hydrophysical characteristics in an area of Acuri palm in the Brazilian Pantanal. Ecohydrology\&Hydrobiology, Vol. 19, Issue 4, 642-650,
DOI: 10.1016/j.ecohyd.2019.04.004.

Saly, R., Bedrna, Z., Bublinec, E., Curlik, J., Fulajtar, E., Gregor, J., Hanes, J., Jurani, B., Kukla, J., Račko, J., Sobocka, J., Surina, B. (2014): Morphogenetic soil classification system of Slovakia. Basal reference taxonomy. Research Institute of Soil Science and Soil Protection. Bratislava, ISBN 978-80-8163-005-7, p. 96

Stekauerova, V., Sutor, J., Nagy, V., Brezianska, K. (2010): Measurement of saturated hydraulic conductivity by Guelph permeameter. Acta Hydrologica Slovaca 2010, vol. 11, no. 2, 349-352.

Surda, P., Stekauerova, V., Nagy, V. (2013): Statistical analysis of soil hydraulic conductivity in the Hron river basin. In: Rožnovský, J., Litschmann, T., Středová, H., Středa, T. (eds): Water, soil and plants, Křtiny. ISBN 97880-87577-17-2. 1-17

WRB, 2014. World Reference Base for Soil Resources (2014): World Soil Resources Reports No. 106. Rome, 192 p.

Zvala, A., Orfanus, T., Stojkovova, D., Nagy, V. (2017): Hydraulic conductivity of superimposed organic horizons. Acta Hydrologica Slovaca, vol. 18., no. 1, 112-119, ISSN 1335-6291.

Mgr. Anton Zvala PhD. ('corresponding author, e-mail: zvala@uh.savba.sk)

RNDr. Tomáš Orfánus PhD.

Ing. Anežka Čelková

Institute of Hydrology SAS

Dúbravská cesta 9

84104 Bratislava

Slovak Republic 